\title{
3D Modelling of a Tunnel Re-excavation in Soft Ground
}

\author{
M. Hilar
}

\begin{abstract}
The construction of the shallow tunnel at Brezno started using the Pre-Vault Method. The tunnel excavation, in complicated geological conditions, led to many difficulties which finally resulted in a collapse, when a significant part of the temporary tunnel lining collapsed. Various options for re-excavating the tunnel were evaluated prior to further construction. Finally a decision was made to separate the collapsed area into sections $9 \mathrm{~m}$ in length using $16 \mathrm{~m}$-wide, transversally oriented pile walls, to improve the stability of the collapsed ground. The walls were constructed from the surface prior to excavation. It was also decided to re-excavate a collapsed area using the Sprayed Concrete Lining (SCL) method. Due to problematic soft ground conditions, which had been made even worse by the collapse, some additional support measures had to be considered prior to re-excavation (ground improvement, micropile umbrellas embedded into the pile walls, etc.)

This paper describes numerical modelling of the tunnel re-excavation through the collapsed area. Initial calculations of the tunnel re-excavation were made using a 2D finite element method. Subsequently, further calculations to evaluate the rock mass behaviour in the collapsed area were provided in 3D. The $2 \mathrm{D}$ calculations were used to provide sensitivity studies, while 3D modelling was mainly used for evaluating the tunnel face stability (impact of the pile walls, impact of ground improvement) together with other factors (length of advances, moment of the temporary invert closure, etc.) The results of the modelling were compared with the monitoring results.

The paper also briefly describes the construction experience (technical problems, performance of various support measures, etc.) The excavation and the primary lining construction were completed in 2006, and the tunnel was opened for traffic in April 2007.
\end{abstract}

Keywords: tunnel, clay, soft ground tunnelling, sprayed concrete, New Austrian Tunnelling Method, NATM, Sprayed Concrete Lining, SCL, numerical modelling.

\section{History}

The construction of the Brezno tunnel, with overburden up to $30 \mathrm{~m}$, started in 2000 using the Pre-Vault Method (Perforex) [1]. The Pre-Vault Method principle is such that a $20 \mathrm{~cm}$-wide slit (for the Brezno tunnel) is cut along the upper and side parts of a predefined tunnel circumference. Step by step, simultaneously with cutting the prescribed number of segments in a prescribed sequence, the slit is filled with sprayed concrete. The hardened concrete forms a protective pre-vault reaching ahead of the rock excavation. The pre-vault has a truncated conical shape. This shape allows overlapping of the individual prevaults. The length of the chain saw determines the length of the pre-vault, which was $5 \mathrm{~m}$ in the case of the Brezno tunnel. The pre-vault can overlap the preceding prevault from 2.5 to $0.5 \mathrm{~m}$ (the excavation advance length is selected according to the geological conditions that are encountered, from 2.5 to $4.5 \mathrm{~m}$ ). Full-face excavation then takes place under protection from the pre-prepared primary lining.

The tunnel excavation was predominantly in plastic clays and claystones, and the maximum thickness of the quaternary deposits (gravels and sands) was about $6 \mathrm{~m}$. The area was also affected by previous undocumented mining activities. The very compli- cated geological conditions caused many difficulties, resulting in a significant collapse in 2003. The collapse occurred when about $860 \mathrm{~m}$ of the primary lining of the tunnel had been completed. About $77 \mathrm{~m}$ of primary lining was destroyed (chain effect of prevaults) and a further $44 \mathrm{~m}$ of the tunnel was filled with collapsed material. Excavation ceased for several months directly after the collapse.

\section{Proposed tunnel recovery}

A decision was made to separate the collapsed area into $9 \mathrm{~m}$-long sections using $16 \mathrm{~m}$-wide tranverse pile walls constructed from the surface. The walls were formed from piles $1.18 \mathrm{~m}$ in diameter, and the walls reached $3 \mathrm{~m}$ below the tunnel profile. The collapsed tunnel was separated into 7 sections in the longitudinal direction. A shaft had to be constructed in the area of a buried Perforex machine (Figure 1).

The Sprayed Concrete Lining (SCL) method was used for re-excavating the collapsed area. The primary lining was designed as sprayed concrete, reinforced by lattice girders and a mesh. The tunnel face had to be excavated in several stages. The proposed excavation method had to be properly statically evaluated prior to application, and all support measures had to be optimised. 


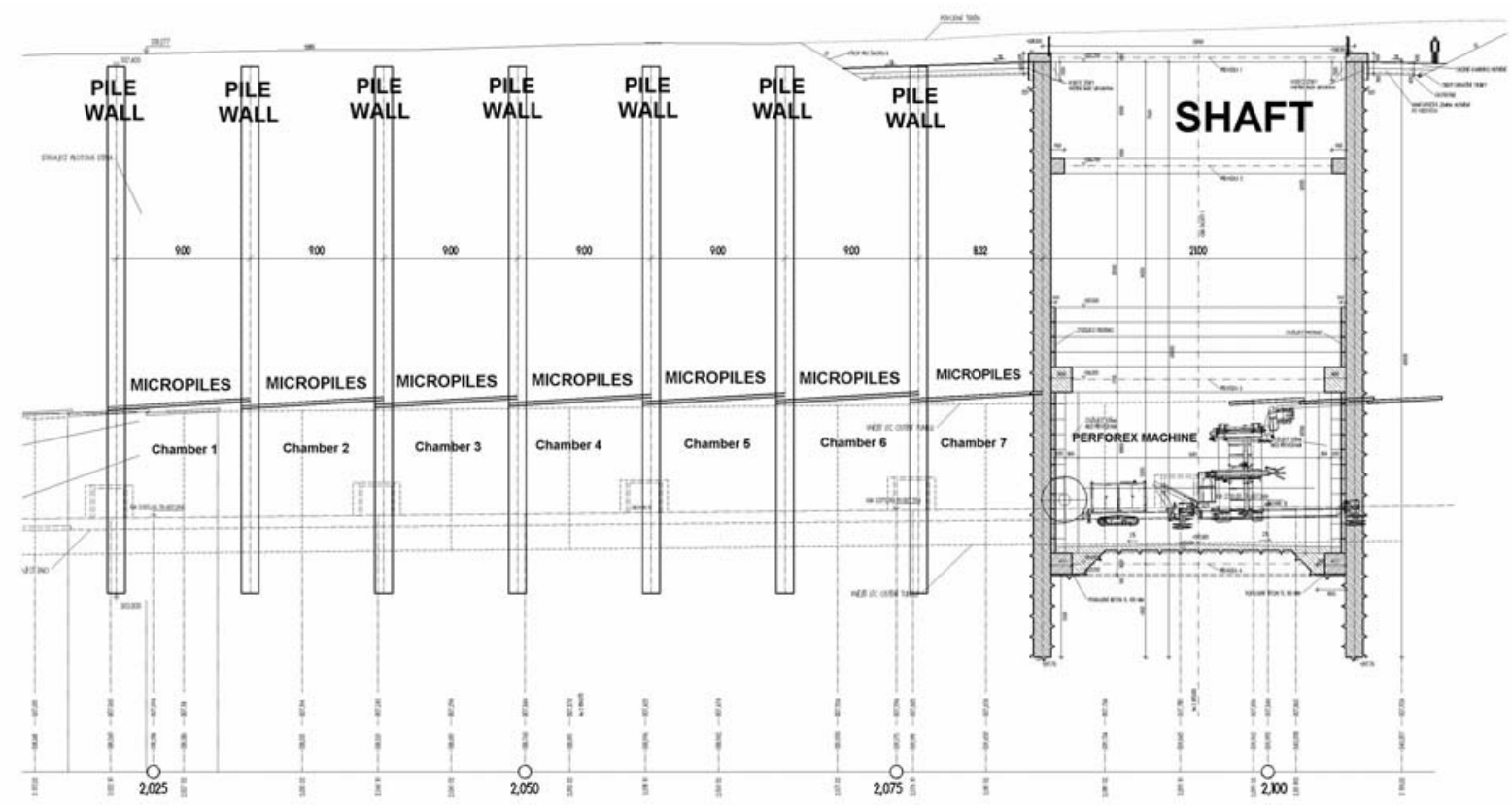

Fig. 1: Longitudinal cross-section, including separation of the collapsed area using pile walls

Table 1: Input geotechnical parameters (the abbreviations of the layers correspond with Figure 2)

\begin{tabular}{|l|c|c|c|c|c|c|}
\hline \multirow{2}{*}{ Geotechnical unit } & \multirow{6}{|c|}{ Input parameters } \\
\cline { 3 - 7 } & & $\gamma\left(\mathrm{kN} / \mathrm{m}^{3}\right)$ & $c(\mathrm{kPa})$ & $\phi\left(^{\circ}\right)$ & $E_{D E F}(\mathrm{MPa})$ & $\nu$ \\
\hline Quaternary deposits & QD & 19.2 & 11.5 & 18 & 17 & 0.30 \\
\hline Strongly weathered claystone & SWC & 19.2 & 11.0 & 10 & 19 & 0.40 \\
\hline Collapsed material & CM & 19.2 & 11.0 & 8 & 19 & 0.40 \\
\hline Weathered claystone & WC & 19.5 & 17.0 & 19 & 19 & 0.40 \\
\hline Claystone A & CA & 19.5 & 36.0 & 19 & 32 & 0.40 \\
\hline Claystone B & CB & 19.5 & 40.0 & 20 & 35 & 0.38 \\
\hline Claystone C & CC & 19.5 & 45.0 & 25 & 50 & 0.38 \\
\hline Coal seam & CS & 19.5 & 30.0 & 25 & 60 & 0.30 \\
\hline
\end{tabular}

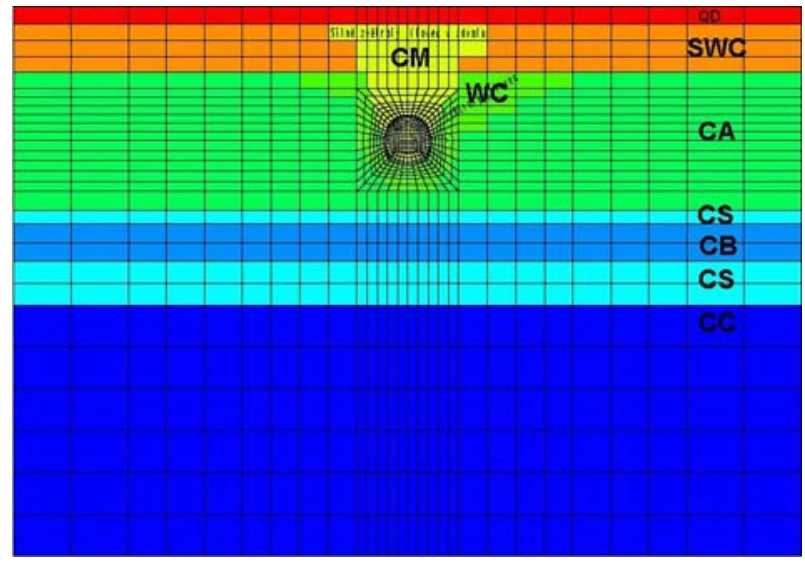

Fig. 2: 2D model finite element mesh (the abbreviations of the layers correspond with Table 1)

The calculations were generated using the finite element method (FEM). Due to the complexity of the problem, ordinary $2 \mathrm{D}$ calculations were supplemented by $3 \mathrm{D}$ calculations to verify some $3 \mathrm{D}$ effects (e.g. impact of tunnel separation by pile walls).

\section{Original calculations}

The initial static calculations for designing the primary lining and the excavation sequence were generated using 2D FEM (plane strain model) [2], and the rock mass was modelled using a linear elasto-plastic Mohr-Coulomb model (Figure 2). RIB software was used for the calculations [4]. The primary tunnel lining was evaluated using interaction curves produced by FINE software [5]. The input parameters were derived from a supplementary site investigation conducted after the collapse. The initial input parameters for each geotechnical unit are summarised in Table 1. The value used for the coefficient of the lateral pressure at rest was 0.8 . The input parame- 
ters were derived from a supplementary site investigation carried out after the collapse. The collapsed ground was quite heterogeneous (a mixture of cohesive and non-cohesive soils), and the selected mean values were rather conservative.

The static calculations that were generated modelled the excavation and support installation in several stages (top heading excavation, top heading lining, bench excavation, bench lining, invert excavation and invert lining closure), and the model included two types of sprayed concrete - three-day-old green sprayed concrete, and sprayed concrete with its final parameters. The lining thickness was $35 \mathrm{~cm}$. The top heading lining was expected to be regularly closed by a temporary invert, which is a crucial measure for achieving equilibrium in geological conditions of this type. Geometry also plays a very important role in minimizing the bending moments (smaller eccentricity) in the lining. The lining geometry was optimised in this way.

The calculated maximal axial forces were in the range $1500 \mathrm{kN}$ to $2450 \mathrm{kN}$, depending on the stage of excavation. The calculations confirmed that the maximum deformations of the primary lining should not exceed $50 \mathrm{~mm}$, and monitoring during construction generally confirmed these expectations. The shape of the temporary top heading invert was designed as a compromise between the optimum static profile and the space requirement for the machinery. The shape of the permanent invert was more appropriate from the static view, as no compromises were required. The tunnel lining evaluation confirmed that its capacity was sufficient.

\section{Verification calculations}

$3 \mathrm{D}$ calculations were generated using Plaxis 3D Tunnel software [6]. The major aim of this modelling was to evaluate the impact of the pile walls on the excavation and the lining. The model was prepared for analysing the conditions input into the $2 \mathrm{D}$ calculations (location of geotechnical units, input parameters, tunnel lining, etc.)

The $3 \mathrm{D}$ model was $127 \mathrm{~m}$ in height, $90 \mathrm{~m}$ in width, and $97 \mathrm{~m}$ in length (Figure 3). The model comprised half of the tunnel, and used symmetry. First, the top heading construction was modelled (Figure 4) in several steps to simulate top heading excavation. Each advance was modelled in two phases (excavation and tunnel lining application).

Second, the bench and invert construction was modelled in several steps (Figure 5). Again, each advance was modelled in two phases (excavation and tunnel lining application). One model was generated with pile walls (Figure 6); the second was generated without them.

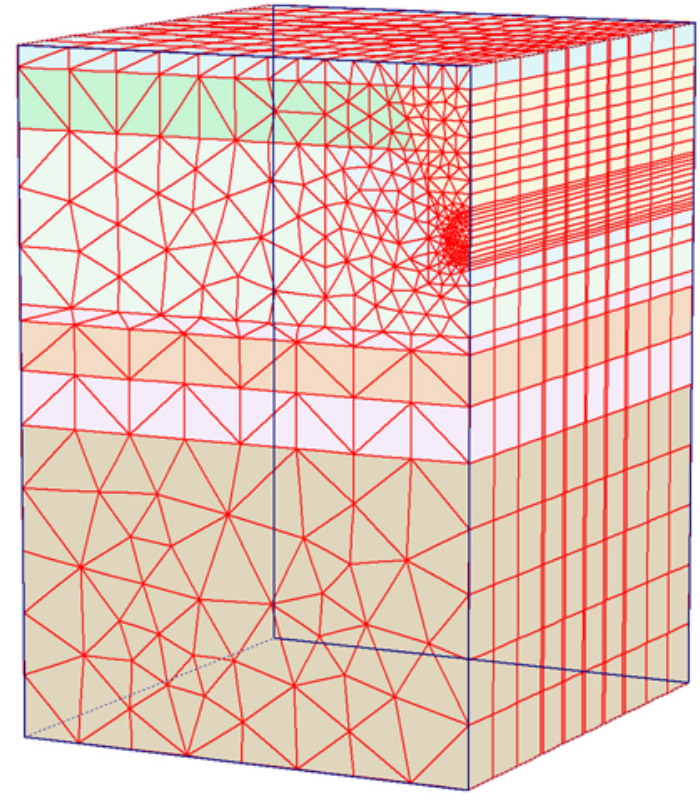

Fig. 3: 3D model finite element mesh (the geotechnical layers and parameters correspond with the $2 \mathrm{D}$ model)

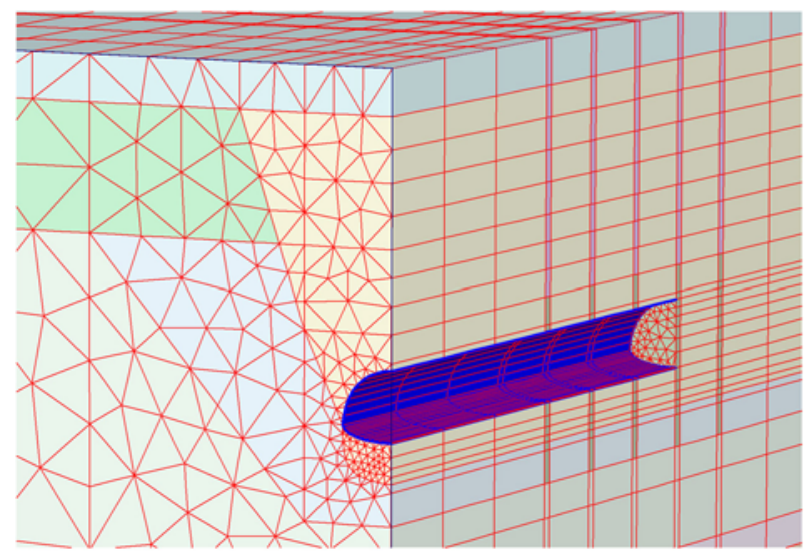

Fig. 4: Modelling of the top heading construction

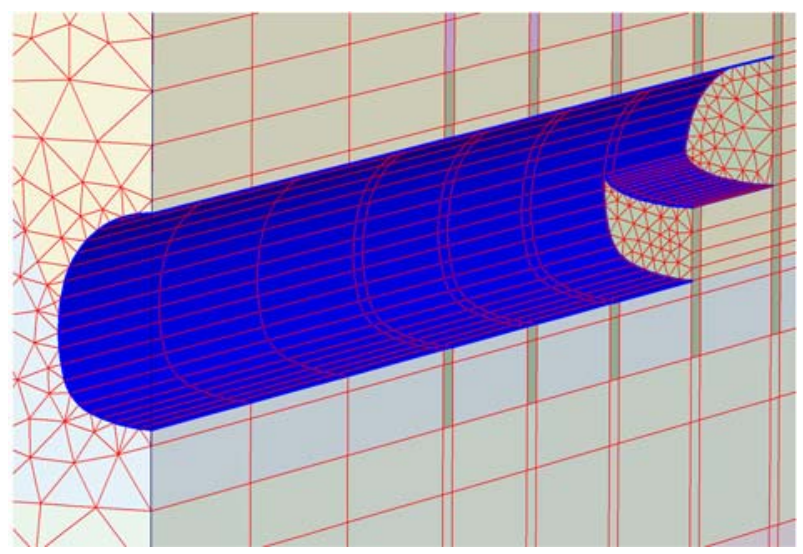

Fig. 5: Modelling of the bench and invert construction 

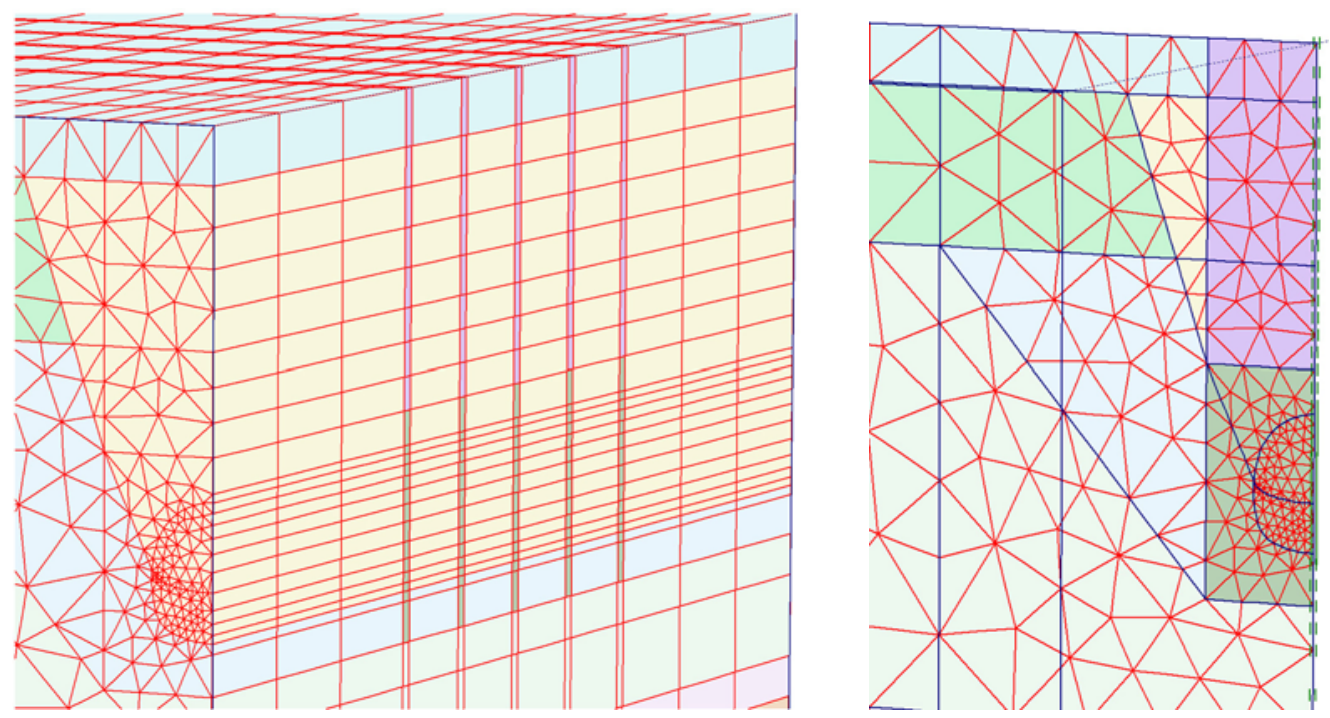

Fig. 6: Details of the 3D model with pile walls

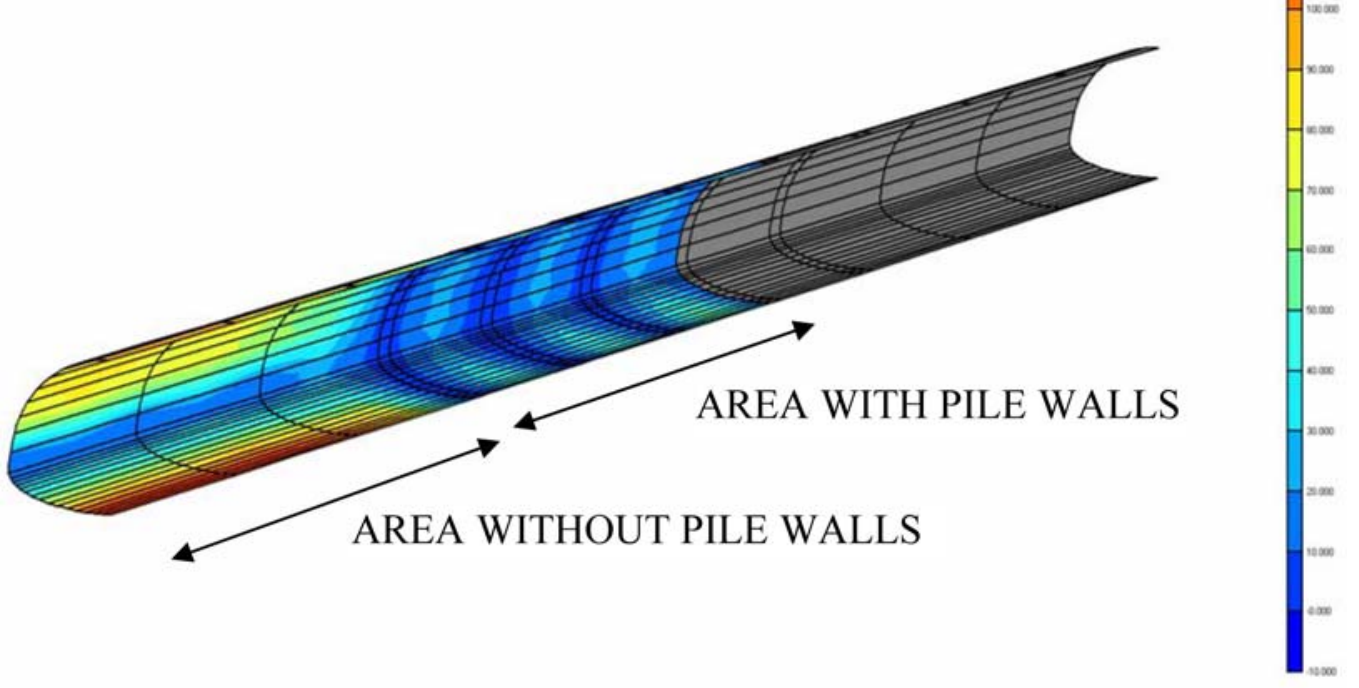

Fig. 7: Top heading tunnel lining deformations (impact of pile walls)

Impact of pile walls: The model included pile walls spaced at $9 \mathrm{~m}$, with a thickness of $1 \mathrm{~m}$ (Figure 6$)$. The pile walls were modelled as a linearelastic material, and they were separated into two parts to simulate the real structure (see Figure 6):

a. Lower part (in the tunnel area) filled with concrete with the properties: $E=25 \mathrm{GPa}, \nu=0.2$

b. Upper part (above the tunnel) filled by suspension with the properties: $E=10 \mathrm{GPa}, \nu=0.2$

Two calculations were generated: with walls and without walls. The results showed the stiffening effect of pile walls. The construction of the pile walls means a reduction in deformations (Figure 7) and bending moments of about $50 \%$. The differences between the $2 \mathrm{D}$ results and the $3 \mathrm{D}$ results (see Table 2 ) were caused by the original estimation of the relaxation. The choice of low relaxation (i.e. a fast ring closure assumption) in the $2 \mathrm{D}$ calculations was determined mainly by taking a conservative approach to the primary lining analysis (to get higher axial forces).

Impact of bench and invert excavation: A further purpose of the $3 \mathrm{D}$ calculations was to evaluate the effect of bench and invert excavation on the 
top heading lining performance (i.e. when the tunnel invert should be closed). The invert was modelled to be closed after $2 \mathrm{~m}$ (Figure 8 ), $4 \mathrm{~m}$, and $8 \mathrm{~m}$ advances. The calculations showed that the values of the internal forces in the top heading lining are not a significant problem. A more significant problem would be the deformations, which would double in the case of $8 \mathrm{~m}$ advances. The next problem was the forces in the longitudinal direction and the shear forces in the lining close to the walls (Figure 9). Thus, a maximum advance of $4 \mathrm{~m}$ was recommended for bench and invert excavation.

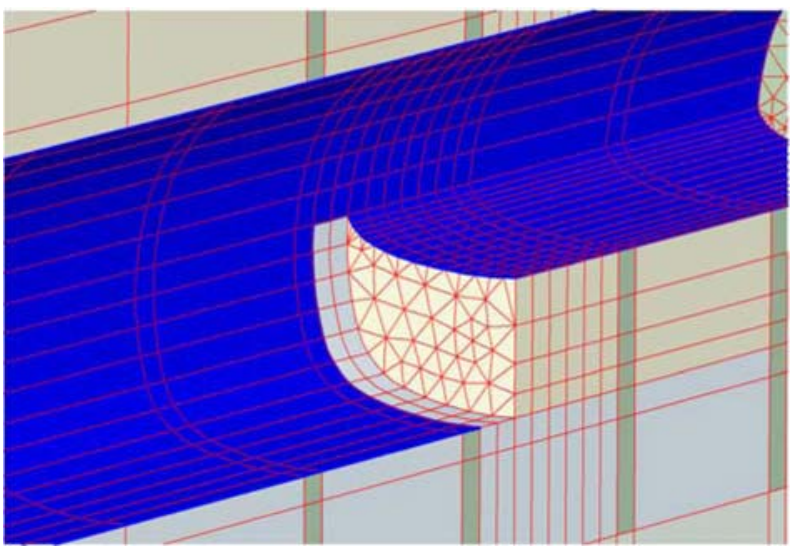

Fig. 8: Bench and invert construction modelling with $2 \mathrm{~m}$ advances

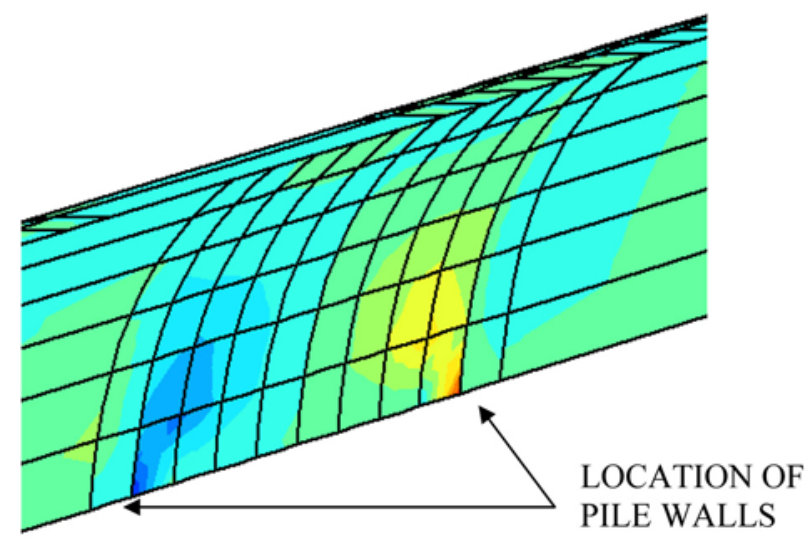

Fig. 9: Concentration of shear forces in the tunnel lining on the interface of the pile walls and the ground

Top heading face stability: Calculations of the top heading face stability were also generated. The bench and invert excavation was expected to be separated at least by one pile wall to have a minimal effect on the stability of the top heading face. Again the calculation was performed in several stages to simulate the tunnel construction procedure (installation of pile walls, consequently several excavations and installations of lining). The tunnel face stability was calculated when the tunnel face was $2 \mathrm{~m}$ behind the pile wall and $1 \mathrm{~m}$ of the excavation was not supported by the tunnel lining. The safety factor was calculated using the phi-c reduction procedure (option available in Plaxis for computing safety factors). In the phi-c reduction approach, the strength parameters $\tan \phi$ and $c$ of the ground were successively reduced until failure occurs. The resulting safety factor is the ratio of the initial and final shear parameters.

The calculations showed a safety factor of 1.1, which indicated problems in the top heading face stability. However, the calculation that was generated did not include the designed support measures (support wedge, micropile umbrellas and jet grouting columns, further sequencing of the face, etc.) The results showed a favourable effect of pile walls in limiting the propagation of the deformations that were generated (Figure 10).

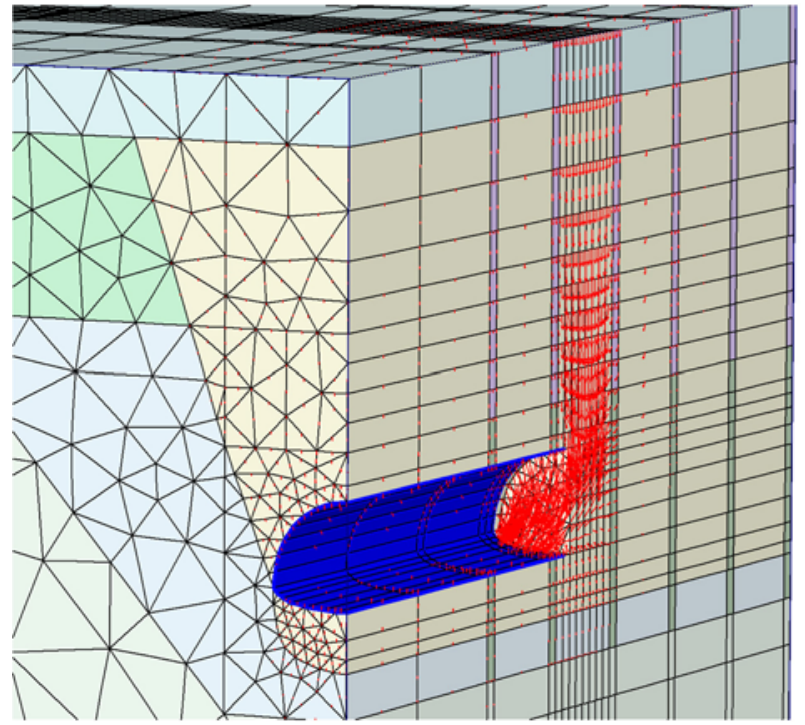

Fig. 10: Propagation of the top heading face deformations

\section{Construction experience}

There was significant anxiety about the ground behaviour prior to the start of excavation, as the area had been significantly disrupted by the previous collapse (the area in and above the tunnel profile). Cores were therefore drilled from the tunnel face prior to excavation of each section between the pile walls, and a decision was made on ground improvement and support measures based on the results of drilling. In chamber 1 (see Figure 1), horizontal jet grouting columns were installed into the face to increase the face stability. This measure was also used in chamber 3 (see Figure 1).

The tunnel profile was regularly protected by micropile umbrellas (Figure 11); the micropiles were embedded into the pile walls on both ends. Some attempts were made to embed the micropiles into 


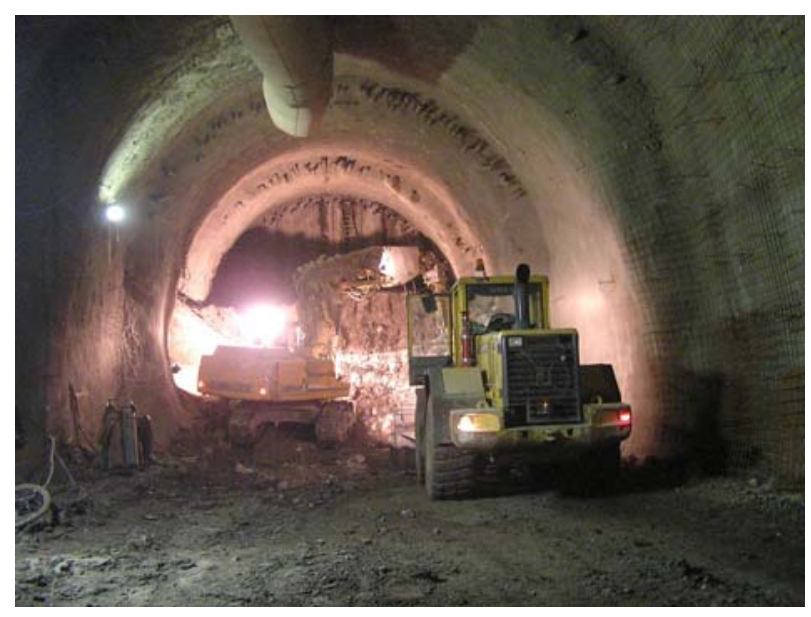

Fig. 11: Tunnel construction under micropile umbrellas

the horizontal jet grouting columns (to increase their stiffness), but like the jet grouting columns drilled into the face, this approach was finished after the third section.

All excavations were done with $1 \mathrm{~m}$ advances. The excavated profile was supported by wire meshes, lattice girders and sprayed concrete. The face stability was regularly increased by a support wedge (ground left in the centre of the excavated profile). In addition, a flash coat of sprayed concrete (several centimetres) was immediately applied on the face and tunnel perimeter after the excavation. The top heading face was sometimes excavated and sprayed in several steps (in cases of local instability). All these measures helped significantly to increase the tunnel face stability, and the calculated low tunnel face stability was confirmed during excavation by several local failures. In addition, the temporary top heading invert was closed regularly. Originally it was closed in $2 \mathrm{~m}$ or $3 \mathrm{~m}$ steps, but later these sections were extended to $4 \mathrm{~m}$. Bench and invert excavation was carried out more than $9 \mathrm{~m}$ behind the top heading face (the length of one chamber). The excavation started at the end of February 2006 and was completed without major problems at the beginning of August 2006.

\section{Results of monitoring}

The ground deformations were recorded by ordinary geotechnical monitoring. The sprayed concrete lining was monitored by convergence monitoring, with three points on the top heading and two points on the bottom. The convergence cross-sections were located in the centre of all pile walls and also between the pile walls (generally one or two intermediate monitoring profiles between two pile walls). The surface settlement was monitored on the top of all pile walls; some intermediate points at ground level between the walls were also monitored.
The maximum surface settlement monitored above the tunnel was $28 \mathrm{~mm}$ (area above the chamber 2). 2D modelling predicted surface settlement of $40 \mathrm{~mm}$, and 3D modelling with pile walls predicted $20 \mathrm{~mm}$. All convergences generally remained below $40 \mathrm{~mm}$, but the monitoring results showed significant scatter of the tunnel lining deformations (Table 2), mainly due to the very difficult heterogeneous ground conditions. In chamber 2, vault settlement of $93 \mathrm{~mm}$ was monitored. This high deformation was caused by local problems (tunnel lining cracking), which did not affect the overall stability of the tunnel. 2D modelling predicted vault settlement of $50 \mathrm{~mm}$, while 3D modelling with pile walls predicted vault settlement of $25 \mathrm{~mm}$. The results are compared with the monitoring results in Table 2.

Naturally, even 3D modelling could not reflect all aspects of the excavation. When the modelling results are compared with the actually measured deformation values, some differences become obvious, but they are not too great in this particular case. The differences are mainly caused by factors which could not be properly included in the models (heterogeneous ground, timing and quality of the support measures, quality of the grouting, etc.)

\section{Conclusion}

The Brezno tunnel had to be excavated in very complicated geological conditions. These ground conditions were significantly worsened by the collapse of a long section of the tunnel lining. The design of the excavation procedure and appropriate support measures for re-excavation of the collapsed tunnel was not a straightforward task. Static calculations of the tunnel re-excavation were provided using the $2 \mathrm{D}$ finite element method (RIB software). Further calculations for evaluating the rock mass behaviour in the collapsed area were provided using Plaxis FEM software. 2D calculations were used to provide sensitivity studies [3], and 3D modelling assisted the evaluation of the tunnel face stability (impact of the pile walls, ground improvement, etc.) The results of the modelling were compared with the monitoring results. The paper also briefly describes the construction experience (technical problems, performance of various support measures, etc.) 2D and 3D modelling were used to evaluate the ground and tunnel behaviour prior to re-excavation.

The modelling provided very useful information prior to the start of construction. It led to optimisation of the tunnel shape and the excavation sequence. It indicated tunnel face stability problems, which had to be improved by various measures. It also showed quite well some anticipated problems which subsequently appeared during the excavation (low stability of the excavation face, concentration of stress be- 
Table 2: Comparison of monitored and calculated tunnel lining crown settlement

\begin{tabular}{|c|c|c|c|}
\hline Tunnel chainage (m) & Monitoring (mm) & 2D Model (mm) & 3D Model (mm) \\
\hline 2004 & 5 & 50 & 25 \\
\hline 2007 & 19 & 50 & 25 \\
\hline 2012 & 21 & 50 & 25 \\
\hline 2019 & 20 & 50 & 22 \\
\hline 2025 & 20 & 50 & 25 \\
\hline 2027 & 27 & 50 & 25 \\
\hline 2031 & 33 & 50 & 22 \\
\hline 2034 & 37 & 50 & 25 \\
\hline 2036 & 50 & 50 & 25 \\
\hline 2040 & 93 & 50 & 22 \\
\hline 2043 & 38 & 50 & 25 \\
\hline 2048 & 39 & 50 & 22 \\
\hline 2052 & 40 & 50 & 25 \\
\hline 2057 & 40 & 50 & 22 \\
\hline 2061 & 40 & 50 & 25 \\
\hline 2066 & 31 & 50 & 22 \\
\hline 2070 & 24 & 50 & 25 \\
\hline 2075 & 26 & 50 & 22 \\
\hline 2079 & 11 & 50 & 25 \\
\hline 2081 & 17 & 50 & 24 \\
\hline
\end{tabular}

tween the unclosed and closed linings, the positive influence of the temporary invert and dividing pile walls, etc.)

Regarding the excavation itself, a flexible approach to the construction work on the part of the contractor was essential. In some cases, it was necessary to respond to the properties and behaviour of the ground in a very flexible manner; it was impossible to optimise all aspects of the excavation in the planning phase. The excavation procedure was reasonably well optimised during construction, so the collapse recovery was completed without any further significant difficulties. The Brezno tunnel construction was successfully completed, and the tunnel was opened for traffic in April 2007.

\section{Acknowledgement}

Financial support from research grant TACR TA01011816 is gratefully acknowledged.

\section{References}

[1] Hilar, M., Heřt, J., Smida, M.: Soft Ground Excavation of the Březno Tunnel. Proceedings of the World Tunnelling Congress, Agra, 2008.
[2] Hilar, M., John, V.: Recovery of a collapsed section of the Brezno tunnel. Tunel, Vol. 16, 3/2007.

[3] Barták, J., Hilar, M., Pruška, J.: Numerical Modelling of the Underground Structures. Acta Polytechnica. Vol. 42, No. 1/2002.

[4] RIB - software for civil engineers. http://www.rib.cz

[5] FINE - civil engineering software. http://www.fine.cz

[6] Plaxis — software for geotechnical engineers. http://www.plaxis.nl

doc. Ing. Matouš Hilar, MSc., PhD., CEng., MICE

Phone: +420604862686

E-mail: hilar@d2-consult.cz

D2 Consult Prague, s.r.o.

Zelený pruh 95/97 (KUTA)

14000 Praha 4, Czech Republic

Department of Geotechnics

Faculty of Civil Engineering

Czech Technical University in Prague

Thákurova 7, 16629 Praha 6, Czech Republic 